\title{
The academic portfolio: Validation of the learning journey
}

\author{
Sandra L. Horton, Debbie J. Drake, Patricia A. Kershaw, Nancy A. Murray \\ School of Nursing, Indiana Wesleyan University, Marion, Indiana, USA
}

Received: June 14, 2019

DOI: $10.5430 /$ jnep.v9n $11 \mathrm{p} 26$
Accepted: July 18, 2019

URL: https://doi.org/10.5430/jnep.v9n11p26

\begin{abstract}
As academicians, students' learning achievements must be described to ascertain programmatic quality and professional accreditation. Additionally, demonstrating accountability is pivotal for application to nursing students' learning in patient situations and leadership decision-making. In this process review, nursing student learning was validated by the use of academic portfolios. Learning was authenticated by having the students identify evidence of their learning applied to school of nursing and program outcomes for nursing administration, the Essentials of Master's Education in Nursing, and the American Organization for Nursing Leadership (AONL) competencies. The AONL competencies were a crucial measurement which enabled students to better view the full scope of their roles as nursing leaders. These academic portfolios provided illustrative vignettes of application of students' learning throughout the master in nursing administration program. Academic portfolios personify the students' learning experiences to validate student learning for academic reviewers, provide continuous quality improvement for nursing programs, and guide the learning application to the students' future careers and lives. These results will also demonstrate program success during an upcoming accreditation survey thus fulfilling a triple objective with one academic project: assessment of student goal achievement, program goal attainment, and accreditation preparedness.
\end{abstract}

Key Words: Academic portfolios (in nursing and healthcare), AONL competencies, The essentials of master's education in nursing, CCNE accreditation

\section{INTRODUCTION}

\subsection{Introduce the problem}

Nursing educators need to verify that students meet course and program outcomes in addition to demonstrating the professional standards for the degrees the students earn. How do we validate that students have achieved these goals and competencies? Educators must be accountable for the answer to this crucial question from a myriad of sources both internally, such as curriculum committees and administration, and externally to entities such as accreditation site visitors, state and federal educational department policy makers, and the public. The most important person for whom we must answer this question is the student. Portfolios can be an important element of the student learning experience because they provide students with the opportunity to visually observe their growth over time and reflect upon the value each experience brings to their development as an expert within their specialty in nursing. This article will focus on the three goals: using academic portfolios for demonstrating student growth, assessing program goal attainment, and indicating program preparedness for an accreditation survey.

\subsection{Explore importance of the problem}

Relevance in learning is essential to students in today's culturally diverse and fast-paced diverse environments. If today's

*Correspondence: Sandra L. Horton; Email: sandra.horton@indwes.edu; Address: School of Nursing, Indiana Wesleyan University, 4201 S. Washington Street, Marion, IN., USA. 
college students are not able to relate the practical value of educational material to their lives, their jobs, and their experiences to date, this disconnect not only decreases the importance of the material but also demotivates the learning process. As students create their portfolios, they are able to assimilate the relevance of the assignment to their current job positions, future nursing leadership careers, and personal lives. The more arenas to which students can apply the competencies from their portfolios, the stronger the application and solidification of their skills become to their personal and professional lives.

One of the complicated factors in demonstrating professional competencies is the means by which these skills are demonstrated. This issue was successfully demonstrated during the development and implementation of a master's degree in nursing administration program at a private university in the Midwest region of the United States. Academic portfolios were utilized to document (a) the achievement of graduate and nursing administration outcomes, (b) application of The Essentials of Master's Education in Nursing, ${ }^{[1]}$ and (c) demonstration of nursing leadership competencies defined by the $\mathrm{AONL}^{[2]}$ wich will to prepare students for the development of professional portfolios after master's degree attainment.

These portfolios represented the students' own words derived from their practical learning experiences through reflection. This article details (a) the learning validation journey, which included benefits and challenges; (b) the academic portfolio process; (c) how portfolios contributed to continuous quality improvement for the masters of science in nursing (MSN) program; and (d) academic learnings gained by faculty along the way. Academic portfolios have stimulated both student and faculty growth along the journey.

\subsection{Describe relevant scholarship}

A literature search was conducted using academic portfolio for key words in the CINAHL Complete database, ERIC - ESBCOHost, ProQuest Nursing \& Allied Health Source, and Health Source: Nursing/Academic Edition. It rendered minimal results related to nursing within the past 5 years. When using nursing portfolios for the key words, the focus of most articles was on a professional portfolio used for purposes such as performance evaluations ${ }^{[3]}$ or to track progression from novice to excellence within a specific nursing specialty. ${ }^{[4]}$ Of particular interest was Green, Wyllie, and Jackson's ${ }^{[5]}$ review of literature on the use of electronic portfolios in nursing education. Few other publications were found related to the use of portfolios with student nurses at the graduate level. Because of the scarcity of literature, the search was expanded to include articles published more than 5 years ago. In doing so, additional articles were found centralized in the 2001 to 2005 timeframe that discussed the inception of the use of portfolios in nursing, ${ }^{[6]}$ but their focus remained on the professional nursing portfolio. To increase the retrieval of literature focusing on academic portfolios, the keywords academic portfolio and educational portfolio were utilized beyond nursing to include other healthcare professionals. The need to expand the scope of a literature search to include additional disciplines in academia was also stated by Green et al. ${ }^{[5]}$ Medicine, radiology, midwifery, pharmacy, and dentistry are healthcare disciplines that utilize academic portfolios to track student development and competency attainment. ${ }^{[7-11]}$ A supportive stance for the use of e-portfolios was common with comments such as "an integrative e-Portfolio experience can help students link and make meaning from various learning experiences" ${ }^{\text {"[12] }}$ and "findings indicated that learning portfolio practice can enhance the nature of the learning experience by providing students with a personal space to evaluate their own learning, to process their thoughts and experience and to document their lives and learning in an authentic and meaningful way". ${ }^{[13]}$ Similar to the skills nurses need to develop, pharmaceutical standards require demonstration of "problem solving, educating different audiences, patient advocacy, interprofessional collaboration, cultural sensitivity, communication, leadership, innovation/entrepreneurship, and professionalism" which Daugherty and Cumberland propose are best suited for expression "via reflective portfolios". ${ }^{[1]}$

\subsubsection{Benefits of academic portfolios}

Bhargava et al. ${ }^{[7]}$ spoke to an increased utilization of portfolios in both academic and employment settings. GadburyAmyot et al. ${ }^{[9]}$ saw a positive correlation between student portfolio quality and grade point average among dental hygiene students. Use of portfolios has both positive and negative connotations within academia. ${ }^{[10]}$ Portfolios have helped pharmaceutical students assess needed measures for accreditation standards. ${ }^{[11]}$ The benefits of portfolios use are provided in Table 1 in section 1.3.1. The categories demonstrate the mutually beneficial outcomes achievable by students, schools of nursing, and eventually the professional nurse administrator with a well-planned academic portfolio program. Upon faculty reflection, there was confirmation that all of the student academic and program assessment benefits were experienced at our institution. Ascertaining professional benefits from the academic portfolio is challenging to determine because universities lose communication with nurses upon graduation. Table 1 is compiled from academic portfolio discussions from seven articles from the literature review. ${ }^{[3,5,6,8,9,14,15]}$ 
Table 1. Categories of benefits from academic portfolio use

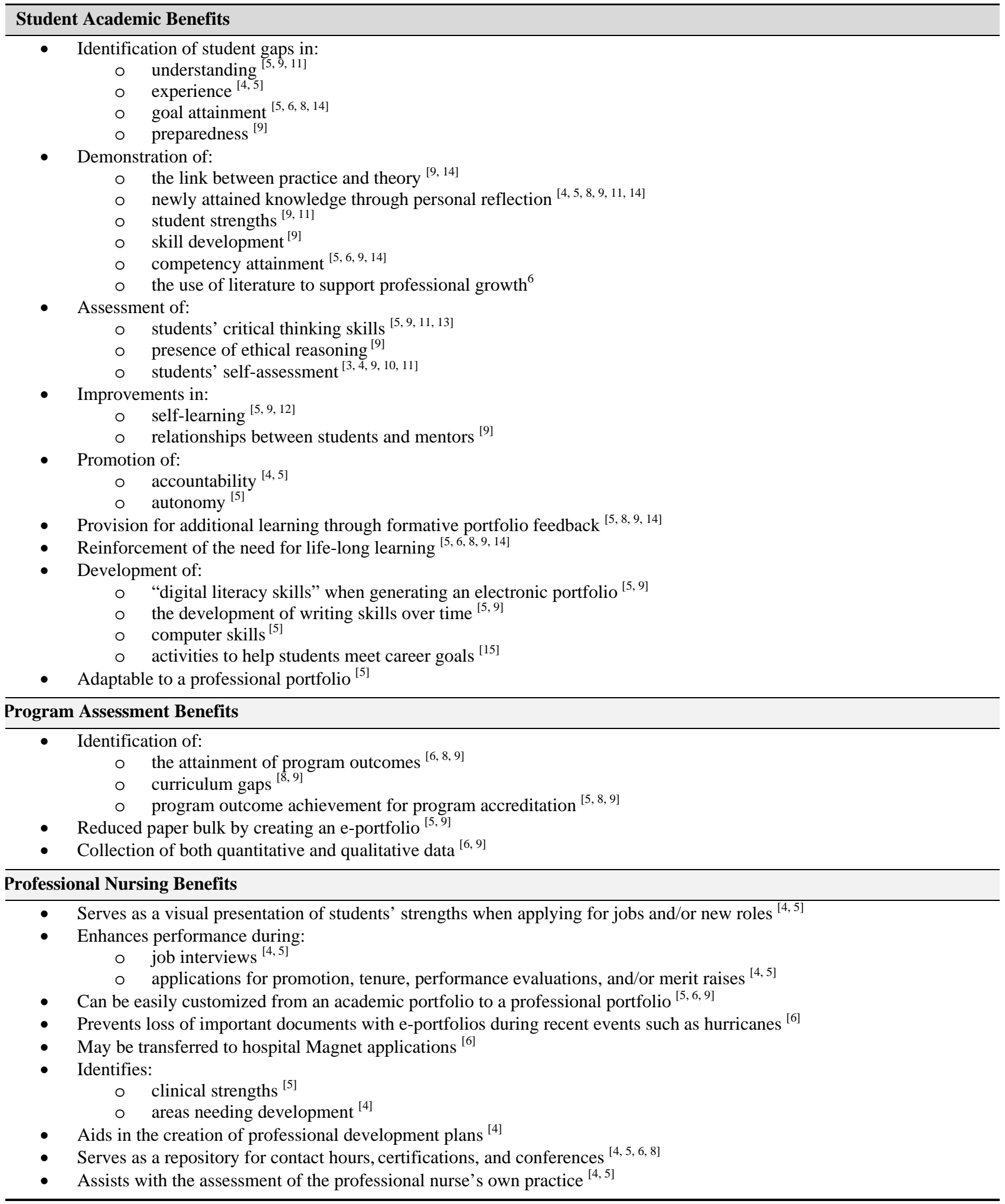

\subsubsection{Challenges of academic portfolios}

Development of best practices takes work in all academic endeavors. This growth requires time and a commitment to work through challenges both unique to a program and recurrent in academia. Common drawbacks to the development of a portfolio are listed in Table 2 in section 1.3.2 as they were gathered from the literature review. A difficult challenge to overcome within the development of an aca- 
demic portfolio is that "incompetent people fail to recognize their own incompetence, while highly competent individuals tend to underestimate their performance." ${ }^{[5]}$ The challenges followed by an asterisk $(*)$ were experienced by our univer- sity. Challenges followed by a diamond $(\diamond)$ were overcome by changing the portfolio process as expressed later in this article.

Table 2. Challenges to academic portfolio use

\begin{tabular}{|c|c|}
\hline Student Challenges & Institutional Challenges \\
\hline - Time to develop the portfolio ${ }^{* \diamond[6,9,11,14]}$ & - Time to grade the portfolio ${ }^{* \diamond[5,9]}$ \\
\hline - The bulkiness to organize a paper portfolio ${ }^{[4,6]}$ & • The provision of meaningful feedback ${ }^{[5]}$ \\
\hline $\begin{array}{l}\text { - The need to document synthesis of knowledge shortly after it } \\
\text { is attained so its recognition is not lost }{ }^{* \diamond[6]}\end{array}$ & $\begin{array}{l}\text { - Having students write "what you want to hear" versus a true } \\
\text { reflection of their learning }{ }^{[5]}\end{array}$ \\
\hline $\begin{array}{l}\text { - Struggles to organize the portfolio contents }{ }^{*} \diamond[8] \\
\text { - Maintenance of the following: } \\
\text { o HIPAA guidelines }{ }^{[5,9]} \\
\text { o Academic integrity }{ }^{[8,9]} \\
\text { - An understanding of what demonstrates competency }{ }^{* \diamond[4,5,9]}\end{array}$ & $\begin{array}{l}\text { - Getting students to own the process of finishing the } \\
\text { portfolio }{ }^{* \diamond[5,9]} \\
\text { - Ensure student efforts are worth the work }{ }^{[5]} \\
\text { - Making appropriate accommodations for students with writing } \\
\text { learning disabilities }{ }^{[5]}\end{array}$ \\
\hline $\begin{array}{l}\text { - A lack of the following: } \\
\text { o Ownership for their own learning }{ }^{[5,14]} \\
\text { o Insight to adequately reflect on their learning }{ }^{[5]} \\
\text { o Writing skills to support portfolio development }{ }^{*[5]} \\
\text { o Knowledge on the portfolio process }{ }^{* \diamond[9]} \\
\text { o Computer skills to support portfolio development }{ }^{*[4]} \\
\text { o Appreciation for the reflective process } \\
{[11,14]}\end{array}$ & $\begin{array}{l}\text { - Maintenance of FERPA guidelines and confidential reflection } \\
\text { content }{ }^{[5,9]} \\
\text { - Establishing trust between the student and faculty }{ }^{* \diamond[5]} \\
\text { - Security of e-portfolios }{ }^{[5]} \\
\text { - Faculty reluctance to let students assume responsibility for their } \\
\text { growth }{ }^{[9]} \\
\text { - Cost of electronic databases to house the portfolio }{ }^{*[6]}\end{array}$ \\
\hline $\begin{array}{l}\text { - A fear of putting their experiences on paper }{ }^{[5]} \\
\text { - Viewing the academic portfolio as busy work }{ }^{[9,14]}\end{array}$ & - Assessment for plagiarism within the academic portfolio ${ }^{*[5]}$ \\
\hline & $\begin{array}{l}\text { - Consistency among graders when assessing the academic } \\
\text { portfolio } * \diamond[5,9]\end{array}$ \\
\hline
\end{tabular}

\section{METHOD}

The method utilized to generate this article was the review of a private Midwestern university's process to develop and implement an academic portfolio program. The reviewers consisted of the four faculty who launched and maintain the academic portfolio process. Early in the curriculum development for the Master in Nursing Administration degree program, the decision was made to incorporate an academic portfolio. The intentions were strong that the academic portfolio needed to be more than a repository for assignments. The portfolio was needed for both student and program assessment. It was to reflect professional development and keep the goals and competencies relevant to nursing administration consistently before the students. What was unique about the process was that there were no findings in the literature reflecting use of the AONL competencies as a method of demonstrating preparedness for the role of nursing administrator and meeting of Commission on Collegiate Nursing Education (CCNE) accreditation standards. The faculty of the nursing administration program felt that the student demonstration of AONL competencies would effectively demonstrate both individual student growth and the university's commitment to produce nursing leaders who were capable to meeting the demands of their roles and the expectations for nursing leaders as set forth by the AONL.

\subsection{Identify the process}

The explanation of academic portfolio process occurred in the orientation course of the MSN program. Each course thereafter reminded students to choose exhibits from that particular course to include in their academic portfolio. A professor graded the completed portfolio in the last course of the MSN program. It was ineffective when students did not have accountability checkpoints between initiation and completion of the portfolio. There also needed to be a consistent faculty member available to students if they had questions or concerns related to their portfolio development.

To address these needs, two courses were created, each worth one credit hour and 2 weeks in length. These courses were named Professional Development A and B. Professional Development $\mathrm{A}$ was the second course in the program, and Professional Development B was the next to the last course. 
The same faculty member who taught Professional Development A also taught the B course and became the student's contact person for academic portfolio issues. Course A included résumé building, professional goal development, and portfolio introduction. Course B included résumé updating, a reflective exemplar on growth throughout the master's program, a growth and development plan for post-graduation, and submission of the completed academic portfolio. Nursing administration students were encouraged to not withdraw from the program when life events created the desire to withdraw. Because of the benefits of the relationship building between the portfolio mentor and the student, faculty worked with students and their life events so that this relationship could be maintained and so that access to the electronic system housing the portfolios was not lost by both the student and the portfolio mentor.

After implementation of these new courses, another decision was made to require two check points on the portfolio one third of the way and two-thirds of the way through the program. The same faculty member who taught Professional Development A and B conducted the two portfolio checks. This way the faculty who taught the student the expectations for the portfolio process was the one evaluating the entire process. This new process worked well to provide students with accountability checkpoints and to allow faculty time to grade portfolios along the way. An added benefit was students received feedback on potential errors that enabled them to correct these mistakes before submitting additional coversheets and exhibits. The due dates for coversheets and portfolios is outlined in Table 3 in section 2.1.

\subsection{Content of the academic portfolio}

The academic portfolio is built on the School of Nursing's outcomes, the program's Nursing Administration Outcomes, The Essentials of Master's Education in Nursing, ${ }^{[1]}$ and American Organization for Nursing Leadership Domains with Indicators for Nurse Executives. ${ }^{[2]}$ The first section in the portfolio contains 35 AONL Domain Indicator coversheets with corresponding exhibits. The second section of the portfolio contains a résumé, professional certifications, continuing education certificates, reflective exemplar, and a growth and development plan. When Course A and B were initially created, students were required to create 56 pairs of coversheets and exhibits to complete their academic portfolio. This was approximately half of the AONL competencies. Both students and faculty found the amount of work required for 56 sets of documentation to be overwhelming. The reduction in the number of demonstrated competencies had positive results beyond reducing the time needed to complete the portfolio. Students produced better quality coversheets and were no longer struggling to find exhibits that barely fit the criteria needed to demonstrate a competency. Faculty had the time to provide better quality feedback which produced additional improvements in student work.

Table 3. Portfolio coversheet and exhibit due dates

\begin{tabular}{lll}
\hline Coversheet \& Exhibit Due Dates & Point in Program & Required Pairs of Coversheets \& Exhibits \\
\hline Professional Role Development A & Course 2 & 2 \\
Checkpoint 1 & $1 / 3$ through program & 6 \\
Checkpoint 2 & $2 / 3$ through program & 12 \\
Professional Role Development B & Second to last course & 15 \\
& & Total of 35 Pairs \\
\hline
\end{tabular}

\subsubsection{Academic Portfolio Section I: Coversheets and ex- hibits}

The coversheet delineated each of the following: (a) the MSN program outcome, (b) the major outcome, (c) the Master's Essential, and the (d) AONL indicator being demonstrated with the chosen exhibit.

- Approximately $30 \%$ of all AONL indicators in each of the five domains required demonstration by using a corresponding exhibit. An exhibit consisted of a preexisting item representing achievement of a competency. Exhibits could be a document, photo, or link to work or an activity to which a student had contributed or produced independently.
- All program and major outcomes in addition to all The Essentials of Master's Education in Nursing were required to be demonstrated.

- The student provided evidence from the literature that the exhibit reflected best practice in nursing administration.

- Each exhibit was validated and supported by two current scholarly sources.

- The reflection section provided an explanation of the student's role in what the exhibit demonstrated.

Reflection is deemed an important component in an academic portfolio: reflection in portfolios offers a link between the- 
ory and practice. ${ }^{[5,16]}$ To reduce variability among faculty grading the academic portfolio, a rubric was established with defined criteria and point values for each section of a coversheet and its exhibit. Appendix A portrays a brief student example of a coversheet.

In our experience, one student reported that other students were utilizing coversheet content shared by previous course participants. A plan is being devised to implement preventative measures to prevent sharing coversheet content in the future. Because the outline of the coversheet contains required repetitive content such as the AONL indicators and the program outcomes, a typical plagiarism checking program is not as helpful as one would hope.

\subsubsection{Academic Portfolio Section II: Additional support- ing documentation}

Reflective exemplar. The exemplar assignment asks students to think back on their MSN journey and reflect upon an occurrence that demonstrates professional growth, especially as it relates to growth in attitude, values, and ethical considerations. Students write from one of two approaches: they envision how they would handle a previous experience differently based upon their newly attained knowledge, or disclose how they exhibited growth by handling a recent situation using skills and wisdom they gained throughout their MSN coursework.

Growth and development. The growth and development assignment requires students to identify AONL competencies $^{[2]}$ in which they feel weak and create a plan to address these shortcomings by proposing a strategy for professional growth after graduation. Students use AONL indicators they were unable to demonstrate to help identify their limitations. Evidence of lifelong learning is a crucial expectation instilled in graduates. Gibbons and Jeschke ${ }^{[17]}$ suggested professional nurses are constantly striving to develop character through ongoing practice and refinement of requisite skills. The academic portfolio helps to accomplish this goal.

\subsubsection{Academic portfolio checklist}

In order to facilitate communication between the student and faculty member grading the academic portfolio, a checklist was developed. The sample Academic Portfolio Checklist uses the term AONE because the American Organization of Nurse Leaders did not change their official name until the spring of 2019, and the student sample was started before this change took effect. The original checklist format contained a line for each of the AONL competencies. This document was too long, and it was difficult for both the student and the grading faculty member to visualize when the required number of coversheets and exhibits had been completed. The checklist was revised into the current version to make its use easier

Published by Sciedu Press for both students and faculty. The AONL competencies have been numbered (with AONL permission) to allow for a brief notation of which competency was submitted by the student. In the new format, faculty enter the AONL number and the date on the checklist when the coversheet was submitted to the data repository.

All coversheets are worth 20 points. The faculty member places the student's score in the second column labeled "Pts" for Points. Because the checklist was created using Microsoft Excel software, the cumulative points show up each time a score is entered. The third column of each section is for the initials of the grading professor. This formatting denotes the number of coversheets and exhibits approved for each AONL domain using color-coded cells. The cells with yellow background indicate how many coversheets were approved during Checkpoint 1 . The cells with pink background indicate how many coversheets were approved during Checkpoint 2 . The cells in blue indicate how many coversheets were approved at the end of the program during Course B.

The section titled Master's Essentials Used allows the faculty member to keep track of which Essentials were used to ensure they are all demonstrated by the completion of the portfolio. Similarly, the School of Nursing (SON) Outcomes and Nursing Administration Outcomes (Nsg Adm Outcomes) columns provide faculty with the ability to track that all outcomes were demonstrated. The additional content required in each academic portfolio is listed in the lower right corner of the academic portfolio checklist. The associated points are listed after the document name, and the earned points are entered into the empty Excel spreadsheet cells for calculation of the student's total portfolio score. The final section of the checklist dendenoteotes the timeframes (Course A, Checkpoint 1, Checkpoint 2, and Course B) when each checkpoint was completed and denotes how many coversheets and exhibits are due each time. This one page format allows students and faculty to visualize portfolio development at a glance.

\subsection{Students' evaluation of the academic portfolio}

The completion of the academic portfolio is a graduation requirement for nursing administration majors, so all nursing administration students participate in this process. Students have the opportunity to evaluate the academic portfolio process by sharing their responses to portfolio development in an End of Course Survey provided during the final portfolio course. These surveys are reviewed regularly; and when appropriate, feedback from students is applied to improve the academic portfolio process. Students report that they like having the 2-week course to finalize their academic portfolios. Affirming comments have been made regarding the 
learning experiences the academic portfolios provide as well as the benefits of how the academic portfolio ties together their learning experiences from across the entire program. Students' comments related to the weaknesses of the portfolio process dealt mainly with two issues: (a) the university's new Learning Management System to which students submit their portfolios, and (b) the clarity of instructions early in the process. ${ }^{[4,5,9]}$ Both of these responses were also found in our literature review in the noted sources. These concerns have been used to improve the process, and student feedback no longer focuses on these issues.

Similar to findings in the literature, ${ }^{[5,10]}$ a few students have resisted the requirement to generate an academic portfolio. One stated he/she was not creating a portfolio, which meant the student would fail the final portfolio course. When the student realized the course would need to be retaken and a portfolio would be needed to pass the course, the process was completed. Two students arrived at Course B with only the coversheets and exhibits from Course A completed. These students needed to compile a complete portfolio before they could complete Course B and meet graduation requirements, which they did. Since the current process was implemented in 2015, no student has failed or appealed the final grading of the academic portfolio. Several students have reported how successful job interviews have been because they used their academic portfolio to showcase their achievements from their master's level education. Two students had such positive experiences with the academic portfolio that they have been hired by the university to serve as portfolio checkers after they graduated with their master's degrees in nursing administration. Their understanding of the process from the student perspective makes them wonderful assets to the faculty team of portfolio graders and mentors.

\subsection{The student evaluation process - Systematic evalua- tion plan}

Faculty use the academic portfolio as an indirect measure for analyzing data for the master's degree Systematic Evaluation Plan (SEP). The resources for the administration major's academic portfolio include the AONL competencies ${ }^{[2]}$ and the American Association of Colleges of Nursing (AACN) Essentials of Master's Education in Nursing ${ }^{[1]}$ in addition to the university's master of science in nursing program outcomes and specific major outcomes. The use of a portfolio to assess student competency and programmatic outcome achievement is consistent with literature. ${ }^{[5]}$ The inclusion of the Master's Essentials ${ }^{[1]}$ is unique based on the literature search that was conducted. Students use each of these resources as they identify an exhibit to meet the criteria for each indicator for which they are providing competency.
The evaluation of the students' academic portfolio is only part of the SEP; it is also evidence to ensure the professional development of the graduate nursing student. It is through students' provision of exhibits demonstrating competencies for the specific AONL indicators ${ }^{[2]}$ that showcases both student professional development and program outcomes are met. These two evaluation points provide a demonstration of the effectiveness of the nursing administration program. Use of the AONL indicators parallels the use of the standardized CanMEDS Résumé which radiology students use to demonstrate proficiency in their roles. ${ }^{[18]}$

\subsection{The program evaluation process: Continuous qual- ity improvement}

A continuous quality improvement (CQI) plan is used by the School of Nursing to review courses assigned in a 2-year rotation. Professional Development Course A and Professional Development Course B both undergo review every two years. The checkpoints between Course A and B and the portfolio requirements are also reviewed during this process. An important reason to have a solid CQI process in place is to ensure there is retrievable evidence of the professional development of the graduate nursing student for both internal program assessment and accreditation surveys. The current CQI process includes resource documents used for the review: end of course student evaluations, faculty feedback, AONL Curriculum Map, AACN Essentials of Master's Education in Nursing, as well as program and major outcomes. The evaluation of the assignments compared to the course outcomes, the AACN Essentials of Master's Education in Nursing, and AONL competencies ${ }^{[2]}$ are the structure used to determine if the content demonstrates the outcomes we wish to meet. This evaluation process determines if the program outcomes and major outcomes are congruent and clearly aligned. Student and faculty evaluations are summarized to help identify needed course improvements and other actions needed as part of the CQI review process.

\section{RESULTS}

Assessment of the portfolio process as well the quality of individual academic portfolios are both part of the SEP. The academic portfolio is introduced when students are novices in graduate work and often report feeling "lost" in the process. The portfolio is developed throughout the entire nursing administrative degree, allowing both the student and the nursing faculty to observe student's growth over time. A yearly assessment process evaluates students' completion of the academic portfolio. A sample of the graded work is pulled from the student population who submitted their academic portfolios. The established benchmark is that $90 \%$ of all student portfolios reviewed meet submission criteria. Student names 
are redacted, and nursing administration faculty hand review for several criteria, which each need to be covered by every student to meet the benchmark. Evidence of application of four key assessment elements (AONL indicators, all program outcomes, all major outcomes, and all Master's Essentials) need to be covered at least once in each portfolio to demonstrate the development of leadership skills, knowledge, and attitudes.

The only years these benchmarks were not exceeded with $100 \%$ compliance were related to specific faculty member grading practices. Upon discovery, the process was revised to have students edit coversheets as appropriate to ensure each of these requirements was fulfilled. This was accomplished by emphasizing the requirement for students to utilize each of the Master's Essentials before the grading faculty member signs off that a portfolio was complete. This benchmark has now been met for the past 2 years.

Aside from reporting the compliance benchmark, faculty grading of the portfolio is also monitored to prevent the inconsistencies mentioned as a portfolio barrier in Table 2 located in section 1.3.2. When assigned grades do not comply with the criteria established in the portfolio grading rubric, full time faculty address the grading approach to help calibrate grading expectations. This helps to standardize expectations for all students creating academic portfolios. These clearly defined criteria help to adhere to academic rigor and reduce student frustration by establishing a specific goal for each coversheet. The use of consistent faculty across the portfolio development process also ensures consistency of grading and empowers an interpersonal relationship that builds between the student and professor. ${ }^{[14]}$

\section{Discussion}

The experience of utilizing academic portfolios for the validation of student achievement of learning, specifically addressing the complexity of graduate and nursing administration outcomes, Master Essentials, and AONL competencies has been a huge undertaking; however, it was well worth the student investment to create the portfolio and the faculty investment to facilitate its development and grading. Additionally, its use after graduation has the potential to boost the professional nurse's financial gains. ${ }^{[4]}$ General support of portfolio use in education is viewed as valuable in producing "work ready graduates". ${ }^{[5]}$ Several limitations were experienced during the development of the academic portfolio process. Not all faculty assigned to teach the course were supportive of the process, and their lack of encouragement and student support was evident in the end products produced by their students when the SEP was performed. There is a lack of literature demonstrating the use of a validated tool with the academic portfolio. ${ }^{[5]}$ The utilization of the AONL competencies supported a well-rounded development of the nursing administrator and demonstrates student participation in activities that reflect competence ${ }^{[6]}$ in a way traditional assessment cannot provide. ${ }^{[9]}$ While this limitation in literature prevented us from replicating and validating a previous study, our successful implementation of an academic portfolio process and writing about its development here will contribute to a gap in literature. An additional limitation of our current portfolio assessment process is that an accreditation survey has not occurred yet. The School of Nursing is due for a survey later this year, and the surveyors' feedback can and will be incorporated into our validation journey. The academic portfolio process has successfully demonstrated that graduate nursing students can be empowered to learn when they get a bird's eye view of how their interaction with the AONL indicators through course assignments and work experiences can truly epitomize and inspire experiences in their personal lives, within their present jobs, and in their future nursing leadership careers.

\section{Conclusion}

In addition to tracking what students have learned during their master's program, faculty have learned significantly about master's level program development while implementing the academic portfolio process. The following discoveries have helped to validate the journey:

- Students needed directions that were simple and to the point. ${ }^{[9]}$

- Students needed templates (examples) of a wellorganized and written academic portfolio. ${ }^{[5]}$

- Students needed to be reminded of upcoming checkpoints in order to have their required exhibits and coversheets prepared for review and grading. ${ }^{[9]}$

- Decreasing the number of required coversheets and exhibits to complete the academic portfolio improved the quality of the coversheets and reflective writings by students because they had more time to dedicate to each of the required elements.

- Finding faculty who are passionate about the academic portfolio is crucial to student success.

- The academic portfolio serves well as both a direct assessment of student goal attainment and as a summative assessment of the program outcome achievement.

Almost all students and faculty are successful at participating in the academic portfolio process. None of our students failed to graduate on time over an incomplete or inferior academic portfolio, although a few have required the undivided attention of gracious faculty to grade completed coversheets for them in order to complete their portfolios at the last minute. 
These academic portfolios personify students' learning experiences to serve the triple purposes of validating student learning for internal and external reviewers; providing continuous quality improvement within the graduate nursing program; and, most importantly, guiding students' learning validation to apply to their future careers and lives. Valida- tion of the learning journey is well-documented when using academic portfolios. Student portfolios can easily be transformed into professional portfolios that document nurses' achievements throughout their life-long careers.

\section{CONFLicts OF InTEREST Disclosure}

The authors declare that there is no conflict of interest.

\section{REFERENCES}

[1] American Association of Colleges of Nursing. The essentials of master's education in nursing. [cited 2011 Mar 2]. Available from: http://www.aacnnursing.org/portals/42/publica tions/mastersessentials11.pdf

[2] American Organization of Nurse Executives. Nurse executive competencies. [cited 2015]. Available from: https://www.aonl.org/sites/default/files/aone/ nurse-executive-competencies.pdf

[3] Capan M, Ambrose H, Burkett M, et al. Nursing portfolio study: the use in annual performance reviews [Abstract]. J Nurses Prof Dev. 2013; 29(4): 182-185. PMid:23877288 https://doi.org/10.1 097/NND . Ob013e31829aec0f

[4] Sinclair PM, Bowen L, Donkin B. Professional nephrology nursing portfolios: maintaining competence to practice. Renal Society of Australasia Journal. 2014; 9(1): 35-40.

[5] Green J, Wyllie A, Jackson D. Electronic portfolios in nursing education: a review of the literature. Nurse Educ Pract. 2014; 14: 4-8. PMid:24090523 https://doi.org/10.1016/j.nepr.2013.08 .011

[6] Dion KW. Nursing portfolios: drivers, challenges, and benefits. Dean's Notes. 2006; 27(4): 1-3.

[7] Bhargava P, Patel VB, Iyer RS, et al. Academic portfolio in the digital era: organizing and maintaining a portfolio using reference managers. J Digit Imaging. 2015; 28: 10-17. PMid:24965274 https ://doi.org/10.1007/s10278-014-9713-0

[8] Finlay K, Probyn L, Ho S. The CanMEDS resume: a useful educational portfolio tool for diagnostic radiology residents. Can Assoc Radiol J. 2012; 63: 233-236. PMid:21873024 https : //doi.org/ $10.1016 / j . \operatorname{carj} .2011 .02 .008$

[9] Gadbury-Amyot CC, Bray KK, Austin KJ. Fifteen years of portfolio assessment of dental hygiene student competency: lessons learned. J Dent Hyg. 2014; 88(5): 267-275.
[10] Birks M, Hartin P, Woods C, et al. Students' perceptions of the use of eportfolios in nursing and midwifery education. J Nurs Educ Pract. 2016; 18: 46-51. PMid:27235565 https ://doi .org/10.1016/j . nepr. 2016.03.003

[11] Daugherty KK, Cumberland DM. The use of portfolios in US pharmacy schools. Am J Pharm Educ. 2018; 82(3): 240-252. PMid:29692438 https : //doi.org/10.5688/ajpe6239

[12] Eynon B, Gambino L, Torok J. What difference can ePortfolio make: a field report from the Connect to Learning Project. IJeP. 2014; 4(1): 95-114.

[13] Farrell O, Seery A. "I am not simply learning and regurgitating information, I am also learning about myself": learning portfolio practice and online distance students. Distance Educ. 2019; 40(1): 76-97. https ://doi.org/10.1080/01587919.2018.1553565

[14] Heeneman S, Pool AO, Schuwirth LWT, et al. The impact of programmatic assessment on student learning: theory versus practice. Med Educ. 2015; 49: 487-498. PMid:25924124 https ://doi .or $\mathrm{g} / 10.1111 / \mathrm{medu} .12645$

[15] Baker S. Book ends. Fast facts for developing a nursing academic portfolio: what you really need to know in a nutshell. [Book review]. Nurs Educ Perspect. 2012; 36(6): 418.

[16] McCready T. Portfolio and the assessment of competence in nursing: a literature review. Int J Nurs Stud. 2006; 44: 143e-151e. PMid:16631759 https://doi.org/10.1016/j.ijnurstu. 200 6.01 .013

[17] Gibbons SW, Jeschke EA. Nursing ethics: a lifelong commitment. Annu Rev Nurs Res. 2016; 34(1): 1-14. PMid:26673373 https://doi.org/10.1891/0739-6686.34.1

[18] Fullick-Jagiela JM, Verbos AK, Wiese CW. Relational mentoring episodes as a catalyst for empowering protégés: a conceptual model Hum Resour Dev Rev. 2015; 14: 486-508. https ://doi .org/10 $.1177 / 1534484315610730$ 